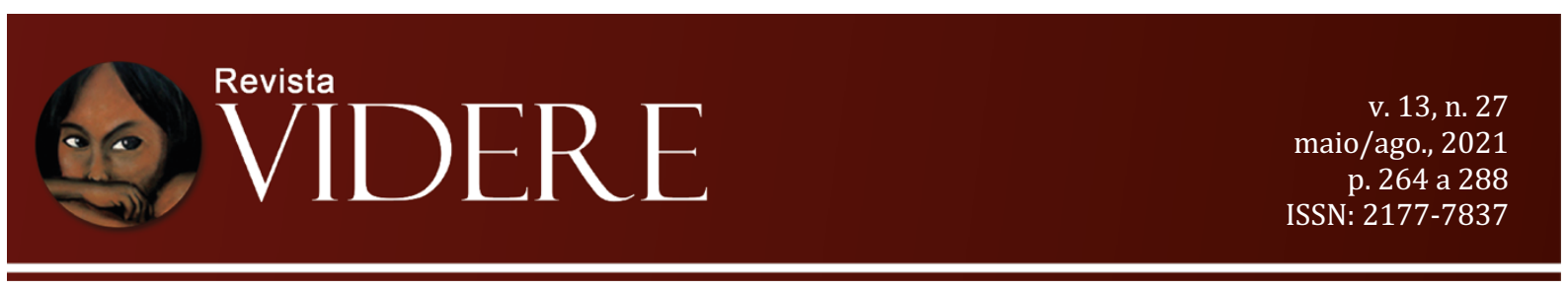

\title{
A DESCOLONIALIDADE E O PARADIGMA DA VIDA CONCRETA NA RESTAURAÇÃO DOS DIREITOS NA AMÉRICA LATINA
}

\author{
DECOLONIALITY AND THE PARADIGM OF CONCRETE LIFE IN RESTORING \\ LATIN AMERICA'S RIGHTS

\section{LA DECOLONIALIDAD Y EL PARADIGMA DE LA VIDA CONCRETA EN LA RESTAURACIÓN DE DERECHOS EN AMÉRICA LATINA}

\author{
Kellyana Bezerra de Lima Veloso \\ Mestra em Teoria e História do Direito \\ Centro Universitário São Lucas Ji-Paraná \\ prof.kellyana@gmail.com \\ OrcidID: https://orcid.org/0000-0002-1310-6715 \\ Raquel Páscoa da Veiga Frade Santana \\ Doutora em Filosofia \\ Centro Universitário São Lucas Ji-Paraná \\ raquelfrade@hotmail.com \\ OrcidID: https://orcid.org/0000-0002-5645-5229
}

Resumo: $\mathrm{O}$ intenso processo de assimilação forçada dos povos indígenas à cultura moderna dizimou grande parte dessas populações na América. A Europa criou um padrão denominado Colonialidade do Poder, que toma o conceito de raça para dominar os povos originários. Esta problemática histórica serve de referência para pensar hoje a situação e os direitos indígenas. Assim, a pesquisa tem o objetivo de verificar se ainda há vestígios de colonialidade na sociedade e quais os impactos dessa presença nos direitos indígenas. Para isso, utilizou-se a categoria da descolonialidade, revelando efeitos práticos para a (não)efetivação dos direitos. Tal categoria proporciona releituras históricas, com questionamentos epistêmicos, teóricos e políticos sobre a realidade desses povos. Resulta que a colonialidade perdura colocando os indígenas na exterioridade e negando a materialidade das suas vidas, sendo necessário o rompimento dessa lógica para a construção de um outro mundo possível e factível.

Palavras-chave: América Latina. povos indígenas. direitos. descolonialidade. paradigma da vida.

Abstract: The intense process of indigenous people' forced assimilation to modern culture decimated a large part of these populations in America. Europe created a pattern called Coloniality of Power, which takes the race's concept to dominate the original people. This 
historical problem serves as a reference for thinking about the indigenous people situation and rights today. Thus, the present research aims to verify if there are still traces of coloniality in today's society, and what are the impacts of this presence on indigenous people rights. For this, it was used the category of decoloniality, revealing practical effects for (non) realization of rights. This category provides historical readings with epistemic, theoretical and political questions about the reality of these people. Results that coloniality endures, placing indigenous people abroad and denying the materiality of their lives, therefore, it is necessary to break with this logic to build another possible and feasible world.

Keywords: Latin America. indigenous people. rights. decoloniality. paradigm of life.

Resumen: El intenso proceso de asimilación forzada de los pueblos indígenas a la cultura moderna diezmó a gran parte de estas poblaciones en América. Europa creó un patrón llamado Colonialidad del Poder, que toma el concepto de raza para dominar a los pueblos originarios. Este tema histórico sirve de referencia para reflexionar sobre la situación y los derechos indígenas en la actualidad. Así, la investigación tiene como objetivo verificar si aún existen rastros de colonialidad en la sociedad y cuáles son los impactos de esta presencia en los derechos indígenas. Para ello se utilizó la categoría de descolonialidad, revelando efectos prácticos para la (no) realización de los derechos. Esta categoría aporta reinterpretaciones históricas, con preguntas epistémicas, teóricas y políticas sobre la realidad de estos pueblos. Como resultado, la colonialidad persiste, colocando a los indígenas en el exterior y negando la materialidad de sus vidas, haciendo necesario romper esta lógica para la construcción de otro mundo posible y factible.

Palabras clave: América Latina. Gente India. derechos. decolonialidad. paradigma de la vida.

\section{Introdução}

No presente texto, refletiremos sobre os direitos dos povos indígenas brasileiros e suas lutas por reconhecimento de direitos historicamente negados.

Desde a invasão europeia, em 12 de outubro de 1492, os indígenas lutaram para serem reconhecidos como humanos, como seres viventes e que querem viver, como sujeitos que necessitam de dignidade e humanidade. Porém, essa humanidade foi negada desde o primeiro contato, pois os povos indígenas foram tratados como seres bestializados, selvagens, sem alma.

O homem europeu, branco, moderno e ocidental logo tratou de assumir a posição salvacionista e civilizacionista, colocando-se como a referência de todas as coisas.

Frei Bartolomé de Las Casas foi o primeiro teórico de que temos registro a defender a noção de que os índios tinham alma e que não deveriam ser escravizados. Além disso, também, afirmou que eles eram os possuidores e legítimos donos das terras em que habitavam (LAS CASAS, 2011). 
Em seu livro "O paraíso destruído: a sangrenta história da conquista da América Espanhola" (2011), aparecem os registros de algumas das polêmicas travadas entre Las Casas e Juan Ginés de Sepúlveda, as quais foram alvo de intervenção da própria Igreja Católica (LAS CASAS, 2011, p. 29).

Entre os vários relatos, destacam-se aqueles que apontam as guerras sangrentas e injustas, responsáveis pela dizimação de mais de quinze milhões de indígenas na América recém-contatada, o que demonstra a ação violenta dos europeus no início do contato.

No Brasil, esse des-encontro é relatado por Darcy Ribeiro (1995) como um choque cruento entre dois mundos, que não eram diferentes somente em suas concepções de vida, morte e amor, mas completamente opostos.

É nesse percurso que se desenhou uma história de resistências e insurgências dos povos indígenas na América Latina.

Assim, o presente trabalho tem por objetivo refletir sobre alguns conceitos e categorias dos direitos indígenas e indigenistas a partir de autores latinoamericanos que se dedicaram a produzir uma literatura crítica sobre a história dos vencidos na América Latina.

\section{A invenção da América Latina e a colonialidade do poder: o eurocentrismo e a modernidade}

Aníbal Quijano é o teórico que criou o termo "colonialidade do poder", a partir dos estudos do Grupo Modernidade/Colonialidade, na década de noventa. Quijano também foi membro do grupo de pensadores latinoamericanos que se debruçaram sobre a teoria da dependência e, juntamente com outros teóricos, como Immanuel Wallerstein, Walter Mignolo, Ramon Grosfóguel, Enrique Dussel, entre outros, organizaram inúmeros seminários e publicações sobre diversas temáticas da América Latina, as quais possibilitaram importantes contribuições para a criação de um novo campo de pesquisas e perspectivas de diálogos SulSul.

Essa nova perspectiva teórica, para se pensar e produzir desde abajo (MIGNOLO, 2000, 260), possibilitou repensar as epistemes ocidentais de caráter universalizantes adotadas para pensar a América Latina.

O saber que se propõe também pode ser denominado como pensamento latinoamericano e abarca várias possibilidades de construção de um outro horizonte de processo civilizatório, desde o Sul, pelo Sul e para o Sul. 
A professora Luciana Ballestrin (2013) destaca a trajetória do Grupo Modernidade/Colonialidade (M/C) e afirma a renovação crítica que o grupo trouxe para as ciências sociais na América Latina no século XXI:

Assumindo uma miríade ampla de influências teóricas, o $\mathrm{M} / \mathrm{C}$ atualiza a tradição crítica de pensamento latino-americano, oferece releituras históricas e problematiza velhas e novas questões para o continente. Defende a 'opção decolonial' - epistêmica, teórica e política - para compreender e atuar no mundo, marcado pela permanência da colonialidade global nos diferentes níveis da vida pessoal e coletiva (BALLESTRIN, 2013, p. 89).

Neste sentido, a pesquisa será orientada pela metodologia descolonial que tem como base a ciência epistêmica, teórica e política com a finalidade de discutir esse modelo de colonialidade ainda dominante no mundo atual.

Ressalte-se que a colonialidade e a modernidade tornam universalizantes conceitos e categorias que não se aplicam a todos os povos e comunidades, especialmente aquelas que vivem fora dos padrões eurocêntricos de produção da vida, na exterioridade do sistema.

Quando a Europa iniciou a sua expansão comercial marítima, acreditando estar no caminho das Índias, pisou no Continente Americano, começando as suas "guerras justas" e a espoliação dos povos que aqui viviam em nome do progresso, da civilização, do cristianismo e da modernização.

A constituição desse padrão de poder, que se expandiu junto com o capitalismo, é denominada de colonialidade do poder, tendo seus pilares fundamentais edificados no eurocentrismo e na modernidade (QUIJANO, 2008, p. 108). Segundo Dussel (1998), a Europa se afirmou como "centro" da história mundial, após do encontro, em 1492, com a América, que se tornou "periferia", sendo um acontecimento constitutivo da modernidade. Em suas palavras, “a Modernidade é realmente um fato europeu” (DUSSEL, 1993, p. 7), noção essa refletida na citação a seguir:

O ano de 1492, segundo nossa tese central, é a data do 'nascimento' da Modernidade; embora sua gestação - como o feto - leve um tempo de crescimento intra-uterino. A modernidade originou-se nas cidades européias medievais, livres, centros de enorme criatividade. Mas 'nasceu' quando a Europa pôde se confrontar com o seu 'Outro' e controlá-lo, vencê-lo, violentálo: quando pôde se definir como um 'ego' descobridor, conquistador, colonizador da Alteridade constitutiva da própria Modernidade (DUSSEL, 1993, p. 8).

Esse "Outro" não foi descoberto e aceito como um ser igual, vivente, mas foi "encoberto" e denominado como imaturo, incapaz, periférico e, assim, foi possível exercer a sua dominação e colonização. 
O europeu, branco, moderno e civilizado, coloca-se como o "ponto de chegada e como espelho futuro dos outros povos" (QUIJANO, 1992, p. 76), e a subalternização de povos nãobrancos e não-europeus foi imposta e justificada como medida necessária para que estes se desenvolvessem e saíssem da condição de barbárie, de atraso, tornando-se, assim, povos civilizados, cristianizados e desenvolvidos, mas nunca iguais aos brancos, tal como relata PortoGonçalves:

O pensamento moderno europeu pouco a pouco vai construir uma geografia imaginária onde as diferentes qualidades dos diferentes povos e culturas, que 1492 pôs em assimétrica relação, serão dispostas num continuum linear que vai da natureza à cultura, ou melhor, da América e da África, onde estão os povos primitivos mais próximos da natureza, à Europa, onde está a cultura, a civilização. E dominar a natureza, sabemos, é o fundamento da civilização moderna construída pelos europeus à sua imagem e semelhança e, para isso, os povos a serem dominados foram assimilados à natureza começando por considerá-los selvagens que significa, rigorosamente, os que são da selva, logo, aqueles que devem ser dominados pela cultura, pelo homem (europeu, burguês, branco e masculino). Vê-se, logo, que a invenção do europeu civilizado é, ao mesmo tempo, a invenção do selvagem e, assim, a invenção da modernidade é inseparável da invenção da colonialidade (PORTOGONÇALVES, 2002, p. 218).

A assimetria dessa relação, destacada por Porto-Gonçalves, revela a pujança com que a Europa se impôs sobre o território recém des-coberto, sobrepondo-se com um direito absoluto e como portadora do espírito do desenvolvimento sobre a periferia (PORTO-GONÇALVES, 2002, p. 218).

Essas relações podem ser vislumbradas a partir dos binômios centro/periferia, atraso/progresso, tradição/modernidade, dominação/libertação, dominador/dominado, europeu/não-europeu, branco/índio, negro e mestiço (QUIJANO, 2005b, p. 6).

Walter Mignolo assevera que modernidade e colonialidade estão imbricadas nesse processo, em especial na América Latina, onde esse sistema se desenvolveu e se expandiu mundialmente:

Não existe modernidade sem colonialidade, que a colonialidade do poder subjaz à construção da nação tanto nas histórias locais das nações que conceberam e implementaram projetos globais como nas histórias locais das nações que tiveram de se acomodar a projetos globais que lhes diziam respeito, mas sem sua participação direta. (...) As Américas, por exemplo, fizeram parte dos sistemas desde seus primórdios (MIGNOLO, 2003, p. 7475). 
Tais categorias, originárias na experiência colonial da América Latina, são constitutivas da colonialidade, reproduzindo-se e desenvolvendo-se de forma universalizante, sendo impostas para todos os outros povos.

$\mathrm{O}$ projeto de modernidade submeteu todo o mundo global à Europa Ocidental, ocultando o caráter negativo (a colonialidade) desse processo que tinha por objetivo atingir o progresso. Logo, todos os percalços no caminho seriam corrigidos com o avanço da modernidade (DAMÁZIO; SPAREMBERGER, 2016, p. 276).

Essas relações, entre europeu e não-europeu, coexistem ao mesmo tempo na materialidade e na intersubjetividade das relações sociais, em que o branco/europeu foi identificado como a referência do mais avançado de todas as espécies. Olha-se tudo a partir desta condição, desta posição, e desta organização que orienta as percepções de mundo segundo as suas categorias, únicas e legitimamente válidas, criando-se, assim, um agir eurocêntrico.

Segundo Quijano (1992), o eurocentrismo é um novo modo de produção (europeia) e de controle das subjetividades, do imaginário e de todo o conhecimento desse novo padrão de poder, fundado na colonialidade, afirmando que:

O eurocentrismo faz parte da colonialidade das relações de poder. Bloqueia a capacidade de autoprodução e auto-expressão cultural, já que pressiona para a imitação e a reprodução. Nas produções do conhecimento, impele para uma perspectiva reducionista, na qual são separados faculdades e modos de experiência e de conhecimento, na realidade exercidos conjuntamente, e faz ver, isolados entre si, elementos da realidade que não existem separadamente. Impede reconhecer não só como necessária, mas como legítima a diversidade, porque só admite como justificativa da desigualdade. Desse modo, bloqueia a capacidade de reconhecer as especificidades de diferentes experiências histórias e de suas implicações para o conhecimento e para a ação (QUIJANO, 1992, p. 74).

O eurocentrismo teve início no século XVII, com a Europa Ocidental, e tornou-se um pensamento hegemônico ao se sobrepor sobre todos os demais povos, sendo uma racionalidade/perspectiva de conhecimento universal (QUIJANO, 2005b, p. 227-228).

O eurocentrismo também é uma categoria fundante da modernidade. A Europa esteve à frente desse processo civilizatório impondo aos demais povos o seu modo de ver e organizar o mundo.

O eurocentramento do controle desse novo padrão de poder exerceu suas influências nos planos político, econômico, intelectual, cultural e geográfico, estabelecendo assimetria nas relações de poder com os não-europeus:

O fato de que os europeus ocidentais imaginaram ser a culminação de uma trajetória civilizatória desde um estado de natureza, levou-os também a 
pensar-se como os modernos da humanidade e de sua história, isto é, como o novo e ao mesmo tempo o mais avançado da espécie. Mas já que ao mesmo tempo atribuíam ao restante da espécie o pertencimento a uma categoria, por natureza, inferior e por isso anterior, isto é, o passado no processo da espécie, os europeus imaginaram também serem não apenas os portadores exclusivos de tal modernidade, mas igualmente seus exclusivos criadores e protagonistas (QUIJANO, 2005, p. 6).

Os conhecimentos, e modos de produção de conhecimento, que não seguiam a lógica eurocêntrica, foram silenciados e categorizados como míticos, inferiores, pré-modernos, não científicos e inválidos, sendo que, somente o pensamento de centro, estabelecido pelas elites científicas e filosóficas da Europa, era considerado como válido e verdadeiro.

Neste sentido, a elaboração europeia de modernidade só foi possível por meio do eurocentrismo e da racionalização dessa perspectiva de superioridade do pensamento europeu, que se sobrepôs sobre todas as áreas da vida, subalternizando conhecimentos que eram distintos.

A hegemonia europeia ocidental proclamou que a modernidade não era um fenômeno exclusivamente europeu, mas sim de todas as culturas, e se afirmou "naturalmente" como protagonista dessa nova perspectiva histórica, instaurando o "mito da modernidade".

Dussel define o "mito da modernidade" como o processo de dominação hegemônico exercido sobre as "sociedades periféricas", composto por algumas características, tais como: a autodescrição de uma civilização superior, de uma civilização mais desenvolvida e de uma civilização responsável por modernizar as sociedades pré-civilizadas, adotando uma posição eurocêntrica (DUSSEL, 2005, p. 29).

Ainda segundo o autor, tal superioridade tem como prerrogativa moral desenvolver os povos tidos como bárbaros, primitivos e imaturos. Para isso, é necessário que a Europa disponha de um processo educativo, que é o espelho dela mesma, um desenvolvimento unilinear e etapista que determina os rumos que devem seguir os povos inferiores, a chamada "falácia desenvolvimentista" (DUSSEL, 2005, p. 29).

O teórico afirma, ainda, que no caso dos povos bárbaros se contraporem à práxis moderna civilizadora, deve-se exercer a violência para se concretizar a modernização, a chamada "guerra justa colonial". Assim, a produção de vítimas e a violência, imposta pela dominação, é considerada um resultado inevitável do conflito. Para ele, aqueles se opõem ao processo civilizador, nomeadamente, os bárbaros, é atribuída uma "culpa", podendo-se colocar a modernidade como "emancipadora" dessa culpa, de suas próprias vítimas (que possuem aspectos de "atrasados", "primitivos", "selvagens", "raças escravizáveis”, “de sexo frágil”, etc.), ou seja, são inevitáveis os custos e os tormentos que lhes são causados para se atingir a modernização (DUSSEL, 2005, p. 29). 
Dussel ainda aponta que tais aspectos são os que constituem o processo civilizatório da modernidade e que negam a "outra-face", a vítima inocente do sacrifício ritual e da conquista violenta, que ao "des-encobrir-se" nega a inocência da modernidade e se afirma, enquanto alteridade, como o Outro negado, ocultado, do "mundo periférico colonial, o índio sacrificado, o negro escravizado, a mulher oprimida, a criança e a cultura popular alienadas, etc." (DUSSEL, 2005, p. 29), ou seja, "as vítimas da modernidade", das identidades rejeitadas pela totalidade do sistema-mundo e que se encontram na exterioridade.

As perspectivas de análise de Quijano e Dussel complementam-se na leitura sobre a modernidade e a colonialidade como faces da mesma moeda e como condição necessária para a solidificação desse padrão de poder que se impôs na América Latina.

\section{A colonialidade do poder como categoria analítica na América Latina}

Em primeiro lugar, é necessário esclarecer ao leitor que existem outros conceitos e outras categorias teóricas importantes para entender o problema da violência colonial, são eles: colonialismo, descolonização, pós-colonial e descolonial.

Tais conceitos, em que pese apresentarem uma aproximação, não são sinônimos e não se desenvolveram de forma conjunta enquanto teorizados pelo mesmo grupo de pessoas e em um mesmo momento histórico. Alguns desses conceitos foram complementares e outros guardam características bem distintas sobre o lugar de enunciação.

Passaremos a expor, de forma breve, para situar o leitor, as categorias que mais interessam neste trabalho, que são as da colonialidade e da descolonialidade.

Começaremos pelo conceito de colonialismo que é distinto da colonialidade. $\mathrm{Na}$ acepção de Ramón Grosfoguel, o colonialismo é a usurpação da soberania de um povo imposta por outro povo, por meio da dominação político-militar de um território e sua população, instalando a administração colonial. O colonialismo exerce a dominação e a exploração política, econômica e cultural sobre um determinado povo e território (GROSFOGUEL, 2007, p. 2). Inglaterra, França, Espanha e Portugal estabeleceram colônias em outros Continentes, em especial na América do Sul e América Central, o que mais tarde viria a se configurar como América Latina e a periferia do mundo.

Já a colonialidade foi definida por Aníbal Quijano como um padrão de poder que perpetua e opera mesmo com o fim do regime político-jurídico das colônias, e se dá pela dominação, exploração e conflito de povos subalternizados, quais sejam os indígenas, negros e mestiços na América, a partir da invasão no século XV (QUIJANO, 2009, p. 73): 
Colonialidade do poder é conceito que dá conta de um dos elementos fundantes do atual padrão de poder, a classificação social básica e universal da população do planeta em torno da ideia de "raça". Essa ideia e a classificação social e baseada nela (ou "racista") foram originadas há 500 anos junto com a América, Europa e o capitalismo. É a mais profunda e perdurável expressão da dominação colonial e foram impostas sobre toda a população do planeta no curso da expansão do colonialismo europeu. Desde então, no atual padrão mundial de poder, impregnam todas e cada uma das áreas de existência social e constituem a mais profunda e eficaz forma de dominação social, material e intersubjetiva, e são, por isso mesmo, a base intersubjetiva mais universal de dominação política dentro do atual padrão de poder (QUIJANO, 2002, p. 4).

Em que pese as colônias terem-se tornado independentes formalmente, elas não se libertaram da continuidade do poder colonial, que agora atua sob outra faceta e nas intersubjetividades dos imaginários sociais, pela diferenciação da raça/cor, do gênero e do trabalho. Tal padrão de poder surgiu com o "des-encobrimento" da América, em 12 de outubro de 1492, e com a expansão do capitalismo moderno/colonial.

O espaço-tempo de permanência desse padrão de poder ainda não cessou; vige em nossa sociedade mesmo depois do fim do colonialismo clássico. O mundo é dividido geograficamente entre Norte e Sul e Ocidente e Oriente. Nas palavras de Quijano, foi o mais efetivo modelo de dominação e exploração já instaurado e que agora se encontra em crise (QUIJANO, 2009, p. 74).

A Europa e, posteriormente, a América do Norte, pretenderam normatizar o mundo global criando um padrão euro-norte-americano que privilegia a liberdade, a criação de direitos, a riqueza e expansão do capitalismo da metrópole, mas nunca da periferia.

Era uma espécie de estágio, no qual se iria "do não-europeu/pré-europeu a algo que com o tempo se europeizará ou modernizará” (DAMÁZIO; SPAREMBERGER, 2016, p. 278).

América (Latina) e Europa se constituem nesse mesmo movimento de expansão do poder capitalista, a Europa como a condutora do processo e a América (Latina) como subalterna numa relação assimétrica de poder ${ }^{1}$.

Esse novo padrão de poder se torna mundial, eurocentrado e tem a colonialidade e a modernidade como seus alicerces (QUIJANO, 2009, p. 74).

A Europa se tornou a propulsora da racionalidade universal e do progresso, com a subordinação dos povos categorizados como inferiores. Mignolo destaca que, com a criação do

\footnotetext{
${ }^{1}$ Faz-se a ressalva que, posteriormente, esse padrão de poder foi reconfigurado e tem a América do Norte também como seu expoente, que passa a figurar agora como a propulsora da nova ordem mundial, em um padrão de poder euro-norte-americano.
} 
sistema mundo moderno/colonial, a Europa se coloca no patamar dos "povos com história" e na condição de inventora da história dos "povos sem história", que se encontravam em um tempo anterior ao presente (MIGNOLO, 2003, p. 23).

Posteriormente, esse processo ocorre também no Brasil pré-colonial, no qual os povos originários são relegados à condição de incapazes e subalternos e, também, o povo negro que foi trazido por remoção forçada da África para trabalhar como mão de obra escrava no Brasil. Darcy Ribeiro (1995) aponta que esse processo se deu de forma extremamente violenta contra indígenas e negros:

O povo-nação não surge no Brasil da evolução de formas anteriores de sociabilidade, em que grupos humanos se estruturam em classes opostas, mas se conjugam para atender às suas necessidades de sobrevivência e progresso. Surge, isto sim, da concentração de uma força de trabalho escrava, recrutada para servir a propósitos mercantis alheios a ela, através de processos tão violentos de ordenação e repressão que constituíram, de fato, um continuado genocídio e um etnocídio implacável. (...) Em consequência, as elites dirigentes, primeiro lusitanas, depois luso-brasileiras e, afinal, brasileiras, viveram sempre e vivem ainda sob o pavor pânico do alçamento das classes oprimidas. Boa expressão desse pavor pânico é a brutalidade repressiva contra qualquer insurgência e a predisposição autoritária do poder central, que não admite qualquer alteração da ordem vigente (RIBEIRO, 1995, p. 23-24).

A par dos conceitos de colonialismo e colonialidade, destacaremos, na sequência, a descolonização e os estudos pós-coloniais, para então compreendermos esses movimentos e do que se tratam.

As lutas pela descolonização referem-se à oposição ao regime colonialista, imposto pelas metrópoles europeias, tendo o objetivo de findar com o regime colonial e estabelecer a liberdade dos povos. Na América Latina, os casos exemplares desses processos de libertação colonial são as de Tupac Amaru, líder indígena peruano que lutou no século XVIII pela libertação do Peru, e a Revolução Haitiana, liderada por Toussaint de L'Ouverture, no Hati, de 1791 a 1804 (PORTO-GONÇALVES, 2008).

Essas lutas por independência são desconhecidas pela maioria da população latinoamericana e desvalorizadas pela colonialidade epistêmica.

A par disso, as lutas por descolonização, enquanto processos políticos de libertação dos povos, realizou-se em diversos locais. Porém, isso não implicou em uma efetiva descolonização das relações de poder nessas sociedades.

Os estudos pós-coloniais, ou teoria pós-colonial, tiveram grande relevância para a difusão do tema na Europa, na Ásia e, somente depois, na América. O termo pós-colonial divide-se em dois significados, o primeiro é o momento de ruptura com o antigo sistema 
colonial, ou seja, o fim das colônias. O segundo significado é empregado para designar os estudos e contribuições teóricas feitas acerca do tema em universidades dos Estados Unidos e da Inglaterra, na década de 1980 (BALLESTRIN, 2013, p. 89):

\begin{abstract}
Os estudos pós-coloniais consolidaram-se entre intelectuais de língua inglesa, via de regra asiáticos, ainda que não só. Destacaram-se, historicamente, como integrantes desse esforço de reflexão desde o palestino Edward Said, passando pelo jamaicano Stuart Hall, até os indianos Gayatri Chakravorty Spivak, Dipesh Chakrabarty e Homi Bhabha. (...) O sensível envoltório do póscolonialismo é tomado por temáticas muito caras ao pós-modernismo teórico, sobre o qual faremos apenas a indicação de que se contenta com os "estudos culturais" e nega a possibilidade de uma totalidade (neste aspecto, a crítica de Quijano é bastante válida). Não à toa, há um compartilhamento de preocupações, por parte dos pós-colonialistas, em torno do multiculturalismo, da discursividade e da desconstrução epistêmica, em especial no seio de áreas disciplinares do conhecimento mais afeitas a essas propostas, tais como as letras e a literatura ou ainda a antropologia (PAZELLO, 2014, p. 90).
\end{abstract}

O grupo de estudos pós-coloniais centrou sua análise na condição subalterna dos sujeitos que foram invisibilizados pelos processos hegemônicos da modernidade. Na obra de Spivak "Pode o subalterno falar?" (2010), a autora destaca a condição subalterna não só como condição da opressão, de exclusão da totalidade, mas também como a impossibilidade de fala dos subalternos e, assim, faz-se necessária a interpelação pelo outro.

Quijano critica os estudos subalternos ou pós-coloniais e seus interlocutores, uma vez que, para ele, a colonialidade nunca se desconstituiu, sendo que esses autores exprimem o seu posicionamento do próprio Ocidente. Daí suas percepções se manterem eurocêntricas, a começar pelo idioma em que escrevem.

Nesse sentido, a colonialidade não é consequência da teoria pós-colonial, conforme afirma Rita Laura Segato (2014), destacando que a formulação crítica desenvolvida por Quijano não só foi um momento de grande ruptura com a teoria crítica nos diversos campos do conhecimento, mas também foi um impulso para a reorientação dos movimentos sociais e da luta política.

Por fim, destacamos o conceito do giro descolonial ou, simplesmente, descolonialidade, que é a destruição total da colonialidade enquanto padrão de poder que domina, explora e oprime grande parcela da população mundial, em especial na América Latina.

A colonialidade é um conceito relacional, pois opera em vários campos como o político, o jurídico, o econômico, dentre outros, produzindo conflitos, por isso a complexidade de identificar e eliminar esse padrão de poder (PAZELLO, 2014, p. 38). 
Desde 1492, a América Latina e seus povos sustentaram o projeto de poder do Centro, nossas subjetividades foram negadas, alienadas e instrumentalizadas para a concreção da modernidade eurocêntrica.

Contudo, esse padrão de poder entra em crise com as insurgências dos povos que vão descobrindo que não só as suas subjetividades foram negadas, mas também as suas vidas, na sua materialidade, e que é necessário a construção de um outro processo civilizatório que afirme as alteridades e não produza vítimas do sistema moderno colonial.

Nas palavras de Quijano, esse processo já está em curso e é inevitável, relata o autor:

O movimento dos mais dominados deste mundo, aqueles que vendem seus meios de subsistência não poderiam existir e, ao mesmo tempo, aqueles que percebem que, se isso acabar, nenhum de nós poderia viver; então finalmente surge outro horizonte de sentido histórico que já está aqui, que já está começando; porque não é apenas o discurso, não são apenas assembleias, estão reorganizando suas comunidades, estão associando suas comunidades, estão gerando outra forma de autoridade política no mundo que terá que competir e entrar em conflito com o Estado, enquanto o Estado ainda está lá. Estamos com outro elemento novo. Isto não é apenas uma utopia, isso está começando; estamos começando a viver com o futuro. Podemos ser derrotados, o mundo pode acabar; mas não há volta para trás (QUIJANO, 2009, p. 5).

Se a colonialidade foi até hoje o lado obscuro da modernidade e a sua sustentação, a descolonialidade é o seu inverso e deve ser a energia e a força geradora para findar com esse padrão de poder que está sendo gestada pelos países periféricos.

A descolonialidade é um processo epistemológico que consiste em expor a lógica da dominação. Portanto, é necessário modificar as formas de fazer e pensar para acabar com a lógica colonial que permeia a política, a economia e o direito (DAMÁZIO; SPAREMBERGER, 2016, p. 276).

Portanto, as perspectivas de produção teórica e prática para o giro descolonial devem, necessariamente, conter uma orientação não eurocêntrica que contradite o sistema mundo europeu/euro-norte-americano moderno/capitalista/colonial/patriarcal.

É necessário descortinar esse horizonte, arquitetado em um imaginário social e histórico, que não é o nosso, assim como é necessário o desprendimento das lentes europeias, que por muito tempo fizeram-nos enxergar como inferiores, periféricos e afirmar as alteridades existentes desde e na América Latina. 


\section{Racialização dos povos indígenas: uma estratégia de poder}

A colonialidade é um padrão de poder inaugurado com a expansão colonial europeia sobre os territórios da América. Para esse específico padrão de poder, a criação da ideia de raça e sua hierarquização irá trespassar todas as demais relações sociais existentes e seguirá vigente mesmo com o fim do colonialismo (QUIJANO, 1999, p. 141).

$\mathrm{Na}$ história das relações de poder entre as gentes (MARÉS, 1998), a estratégia de racialização de povos categorizados como inferiores foi o mais eficaz instrumento de dominação social e é o elemento fundacional da colonialidade do poder.

Inventa-se o termo raça por volta dos séculos XV e XVI para a exploração dos territórios colonizados pela Europa e que possui elementos necessários para o controle da sociedade e da produção inaugurada com a modernidade e com o paradigma eurocêntrico, mas não só isso, a ideia de raça afeta todas as outras dimensões da vida porque discrimina saberes e produções, reduz civilizações, valores, capacidades, criações e as crenças dos vencidos na história colonial (QUIJANO, 2014, p. 54).

A construção científica de que os "povos de cor" eram biológica e naturalmente inferiores foi produto da elaboração europeia. Trata-se de uma construção ideológica de um padrão de poder moderno/colonial e eurocentrado e que nada tem a ver com as diferenças biológicas e fenotípicas humanas, como foi sustentado pelo racismo científico durante muito tempo, conforme Quijano:

A idéia de que os dominados são o que são, não como vítimas de um conflito de poder, mas sim enquanto inferiores em sua natureza material e, por isso, em sua capacidade de produção histórico-cultural. Essa idéia de raça foi tão profunda e continuamente imposta nos séculos seguintes e sobre o conjunto da espécie que, para muitos, desafortunadamente para gente demais, ficou associada não só à materialidade das relações sociais, mas à materialidade das próprias pessoas (QUIJANO, 2005, p. 17).

Este sistema de dominação recaiu sobre os indígenas da América e sobre os povos negros da África que foram dominados e explorados dentro de regimes escravistas e de servidão nas colônias instaladas nas Américas: um processo histórico impactado por saberes e por poderes resultantes da colonialidade, que justificou a destruição das subjetividades indígenas e negras, a negação de direitos e a tomada de seus territórios:

A vasta e plural história de identidades e memórias (seus nomes mais famosos, maias, astecas, incas, são conhecidos por todos) do mundo conquistado foi deliberadamente destruída e sobre toda a população sobrevivente foi imposta uma única identidade, racial, colonial e derrogatória, "índios". Assim, além 
da destruição de seu mundo histórico-cultural prévio, foi imposta a esses povos a idéia de raça e uma identidade racial, como emblema de seu novo lugar no universo do poder. E pior, durante quinhentos anos lhes foi ensinado a olhar-se com os olhos do dominador. De modo muito diferente, mas não menos eficaz e perdurável, a destruição histórico-cultural e a produção de identidades racializadas teve também entre suas vítimas os habitantes seqüestrados e traídos, do que hoje chamamos África, como escravos e em seguida racializados como "negros". Eles provinham também de complexas e sofisticadas experiências de poder e de civilização (ashantis, bacongos, congos, iorubas, zulus etc.) (QUIJANO, 2005, p. 17).

Para Quijano, a invenção da ideia de raça foi uma construção mental sem lastro na realidade para naturalizar as relações de poder, associando trabalho não pago com os povos dominados, porque os consideravam inferiores:

As diferenças fenotípicas entre vencedores e vencidos foram usadas como justificação da produção da categoria 'raça' embora se trate, antes do mais, de uma elaboração das relações de dominação como tais. A importância e a significação da produção desta categoria para o padrão mundial do poder capitalista eurocêntrico e colonial/moderno dificilmente poderia ser exagerada: a atribuição das novas identidades sociais resultantes e sua distribuição pelas relações do poder mundial capitalista estabeleceu-se e reproduziu-se como a forma básica da classificação societal universal do capitalismo mundial; estabeleceu-se também como o fundamento das novas identidades geoculturais e das suas relações de poder no mundo. E, também, chegou a ser parte por detrás da produção das novas relações intersubjetivas de dominação e de uma perspectiva de conhecimento mundialmente imposta como a única racional. A 'racialização' das relações de poder entre as novas identidades sociais e geoculturais foi o sustento e a referência legitimadora fundamental do caráter eurocentrado do padrão de poder, material e intersubjetivo. Ou seja, da sua colonialidade (QUIJANO, 2002, p. 106-107).

Assim, a Europa constituiu o capitalismo mundial com uma estrutura de produção, acumulação, exploração e controle do trabalho, criando relações dependentes históricoestruturais que podem ser visualizadas nas diferenças entre centro e periferia.

Destaca-se que esse padrão de poder só foi possível concretizar-se com a racialização dos povos indígenas e negros que, para Quijano, é o eixo de sustentação dessa estrutura, pois ao serem considerados como inferiores, subalternos, sem humanidade, eles deveriam realizar o trabalho não pago e explorado por pessoas que os submeteram à condição de coisa, de res, como não sujeitos, totalmente sem direitos.

A cessação posterior das relações coloniais não foi superada com a descolonização formal, como sustenta o projeto da modernidade. Quijano aponta que as formas coloniais de dominação se perpetuam sob outras estratégias de poder, visto que não existe modernidade sem colonialidade. 
A perspectiva da descolonização das relações materiais de poder, na América Latina, é o ponto de partida de todo esse debate e do projeto de libertação dos povos subalternizados, para que seja possível romper com a hegemonia do paradigma eurocêntrico das relações sociais (QUIJANO, 1992, p. 79).

Mesmo com as transformações políticas, apoiadas num modelo republicano, no que diz respeito aos povos indígenas e tradicionais, não se constataram alterações substanciais que garantissem a proteção de seus direitos.

Não obstante essas transformações, perpetuou-se o padrão de poder da colonialidade, mas agora encoberto por outras estratégias, que no entanto mascaram a realidade e, novamente, colocam os indígenas numa condição subalterna, propondo que estes sejam integrados, pacífica e harmoniosamente, à comunidade nacional.

Esta perspectiva de integração, baseada no paradigma assimilacionista, foi incorporada na política de Estado e respaldada no ordenamento jurídico, inclusive como diretriz de atuação do Serviço de Proteção ao Índio e Localização de Trabalhadores Nacionais (SPI), órgão criado em 1910 e responsável pela política indigenista do Estado.

Nesse período, registra-se a tônica de violência e de crueldade a que os povos indígenas foram submetidos, documentada no Relatório Figueiredo (1967) e no Relatório da Comissão Nacional da Verdade (2014), constatando-se: a dizimação de alguns povos indígenas, torturas que foram praticadas contra eles, violências físicas e simbólicas, entre outros atos que ferem totalmente a dignidade e os direitos dos povos indígenas.

Somente em 1987, com o processo constituinte, conquista-se, pelos movimentos indígenas, o reconhecimento de direitos, incluídos no capítulo indígena da Constituição de 1988, assegurando-se, constitucionalmente, o direito de ser povo e os direitos originários sobre as terras que os povos indígenas ocupam, rompendo-se, assim, com o paradigma assimilacionista.

Porém, mesmo com este avanço normativo significativo, não é possível ignorar o intenso processo de aculturação promovido pelo Estado ao qual foram forçados desde a invasão europeia. Exemplo disso, é o intenso avanço das fronteiras agrícolas e minerárias sobre as terras indígenas, mesmo após tais terras terem sido destinadas à posse permanente e usufruto exclusivo dos indígenas.

Em que pese os avanços jurídicos conquistados, a retórica jurídica relativiza ou suprime os direitos indígenas quando estes se contrapõem aos interesses do capitalismo. $\mathrm{Na}$ nova geografia de poder, e da divisão internacional dos recursos naturais, é cada vez mais gradativo o avanço das fronteiras agrícolas e dos grandes projetos de "desenvolvimento 
nacional" sobre as terras indígenas, para a produção energética, mineral/extrativista, atividades eletrointensivas e a extração de commodities.

Fato é que, não raras vezes, as portas do judiciário estão sempre fechadas para as demandas dos povos indígenas, mantendo um pluralismo formal legal, que não possibilita real de mudança, o que se revela em mera retórica jurídica e exclusão dos povos indígenas do sistema de justiça, fazendo com que estes se encontrem na exterioridade, à margem do sistema.

A necessidade de união dos povos indígenas, na luta pela terra e pela manutenção de seus direitos étnicos e coletivos, ganha novos desafios e requer a afirmação dos diversos povos indígenas enquanto sujeitos históricos de um mesmo processo de dominação e exploração conduzidos pelo grande capital.

Neste sentido, ocorre apenas uma mudança de estratégias, encobertas sob o pretexto de proteção, que dominam e controlam as subjetividades e direitos dos povos indígenas.

\section{A lógica da totalidade e da exterioridade na relação do Estado com os povos indígenas}

Neste ponto, abordaremos as noções de totalidade e exterioridade, a partir das leituras de Enrique Dussel e Celso Ludwig e, ainda, situaremos porque os povos indígenas estão fora da totalidade do sistema político, econômico e jurídico, encontrando-se na exterioridade do sistema mundo moderno colonial.

A reflexão filosófica latinoamericana, especialmente da Filosofia da Libertação de Enrique Dussel, reclama que o atual paradigma filosófico ocidental (paradigma da linguagem) não contempla a realidade do terceiro mundo em que grande parte das populações experimentam os mais diversos tipos de violações de dignidade e de direitos.

Na periferia do mundo latinoamericano e caribenho, as experiências de negação da concretude da vida são experimentadas pela maioria da população, em sua própria corporalidade e pela impossibilidade de realização material da vida, tornando-os vítimas do sistema, excluídos e afetados da comunidade real.

Para tanto, reivindica-se o reconhecimento de um quarto paradigma filosófico, o da vida concreta ou do paradigma da vida, para dar conta dessas realidades (LUDWIG, 2011).

No caso dos indígenas latinoamericanos, essa exterioridade da vida negada, do nãoser, não foi superada com os processos descolonizatórios, nem com a posterior, e tão recente, inclusão formal dos direitos dos povos indígenas, expressos na Constituição brasileira de 1988 e nas demais Constituições latinoamericanas, como afirma Ludwig: 
$\mathrm{Na}$ conquista histórica da América pelos europeus (Espanha e Portugal, inicialmente), houve o encontro com o Outro (o indígena). Esse outro foi aniquilado, negado e incluído no mundo de centro como coisa (a relação sujeito-objeto na práxis). O outro foi aniquilado pela eliminação física, ou como sujeito, tornando-se instrumento a serviço do "mesmo" (LUDWIG, 2011, p. 113).

O "Outro", segundo o autor, é excluído do sistema mundo porque é o diferente, e a diferença, necessariamente, é identificada como o mal nas totalidades, devendo ser conduzida ao "mesmo", ou seja, "o mal é a diferença, o bem é a volta do mesmo, à totalidade (LUDWIG, 2011, p. 111)", é a redução da multiplicidade à unicidade.

As vítimas, mesmo não intencionais, são excluídas e silenciadas dos consensos produzidos nos processos decisórios, embora recebam os efeitos desses consensos do qual não fizeram parte. Hoje, são mais de dois terços das pessoas do mundo atual (LUDWIG, 2011, p. 109) e é a realidade da América Latina; os excluídos, os oprimidos, os condenados da terra.

Para que a vida negada das vítimas tenha a possibilidade de se tornar vida concreta, vida afirmada, é preciso romper com as totalidades e afirmar a produção, reprodução e desenvolvimento da vida dos sujeitos em comunidade, que se encontram na exterioridade. Além disso, é preciso romper com o modelo hegemônico e criar um projeto factível de uma nova realidade que não produza vítimas.

Ludwig afirma que, para suplantar a retórica da exaltação dos direitos e do desenvolvimento pautados pelo mundo moderno, devemos realizar um pensamento crítico e contra-hegemônico, proposto pela filosofia da libertação e alicerçado num projeto transmoderno, construído com base no paradigma da vida que interpele pelo Outro:

O que o ocorre é que a civilização do capital - para outros a civilização moderna - é que produz em sua lógica e em sua práxis relações sociais e sistêmicas de massiva violação dos direitos humanos. Produz relações de negação da mais elementar condição humana. E nas perspectivas das causas, a fonte maior dessas violações, ou seja, aquela que supõe a violação mais grave e está na raiz das demais violações, é a violência estrutural: a violência da civilização do capital (quiçá moderna) que coloca a imensa maioria da humanidade em condições biológicas, econômicas, sociais, políticas, culturais e jurídicas em rigorosa precariedade, em condições desumanas (LUDWIG, 2014, p. 30-31).

A realidade brasileira é excessiva nos exemplos de exterioridade vivenciada pelas vítimas do machismo, as vítimas do racismo, as vítimas do sistema político, as vítimas do sistema de justiça, as vítimas do sistema econômico, as vítimas do sistema pedagógico, dentre outros tantos. Contudo, em conformidade com o tema até aqui abordado, trataremos do caso dos indígenas brasileiros, que é um dos exemplos mais simbólicos e sintomáticos de uma 
sociedade que negou suas vidas, subjetividades e direitos para contemplar os interesses políticos e do mercado.

O Estado brasileiro sempre manteve uma relação de incompreensão com os povos indígenas. Primeiro, na tentativa de extermínio e limpeza étnica, depois na relação tutelar e, posteriormente, numa relação de afirmação de direitos, mas não necessariamente de sua efetivação.

O caso dos povos indígenas, no Brasil, carrega ainda o peso do des-encontro do branco e do indígena, sobretudo da violência colonial imposta sobre os povos originários. Após quase quinhentos anos de conflito, reconheceu-se, somente em 1988, o direito de permanecerem para sempre como indígenas (SOUZA FILHO, 2006) e, frisa-se, somente em 1988.

Vê-se que a promessa constitucional ainda não se efetivou, e está longe disso, principalmente, porque temos uma cultura jurídica monista, autoritária, que recebe grande influência das matrizes europeia e anglo-saxônica. Também, porque a leitura que se faz do direito ainda carrega forte presença do individualismo e da hegemonia da propriedade privada, desprivilegiando a interpretação e efetivação dos direitos étnicos e coletivos.

O capítulo indígena da Constituição Federal de 1988 é considerado um grande avanço no direito indigenista brasileiro, sobretudo no reconhecimento originário das terras que, tradicionalmente, os povos indígenas ocupam. Porém, diversas são as estratégias jurídicas e políticas para que tal direito não se concretize, a mais recente é a inconstitucional tese do marco temporal demarcatório, que objetiva considerar que somente serão demarcadas as terras indígenas que estavam sendo ocupadas e defendidas pelos indígenas em 05 de outubro de 1988, data da promulgação da Constituição.

Diversas também são as propostas legislativas tramitando no Parlamento para que as terras indígenas deixem de ser espaços de posse permanente e usufruto exclusivo dos indígenas, abrindo as terras para a exploração do capital. Tais propostas, além de contrariar a vontade dos povos, ainda afrontam significativamente o texto constitucional.

Frisa-se que os povos indígenas têm uma relação diferente com a terra e com os recursos naturais provindos dela, que não é a mesma relação que a grande parte da sociedade não-indígena tem com a terra, por vezes, meramente para a acumulação de capital. Há, assim, uma relação de dependência dos povos indígenas com a terra, para além da questão material.

$\mathrm{A}$ indissociabilidade entre a terra e a vida dos povos indígenas é incompreendida pela maioria da sociedade, segundo defende Maria Rita Kehl, a relação intrínseca entre terra e vida para os povos indígenas é o fio que dá sentido à vida, mesmo quando não há vida, pois os indígenas não abandonam os seus mortos: 
A razão dos guarani para permanecer na terra é um pouco mais sofisticada. Eles não admitem abandonar seus mortos. Que por sua vez foram assassinados porque se recusavam a abandonar a terra de seus mortos mais antigos - e assim por diante. $\mathrm{O}$ fio que dá sentido à vida deles não se rompe com a morte dos antepassados. (...) $\mathrm{O}$ que eles reivindicam não é a propriedade, é o pertencimento. Não é a terra "deles", embora saibam que a lei do branco exige papel passado. Não é a propriedade, é a terra à qual eles pertencem. Essa língua é mais estrangeira ao capitalista do que a própria língua indígena. A terra não é posse, não se troca por dinheiro, não serve para especular. Serve para você saber quem você é (KEHL, 2013).

Essa junção entre vida e terra, ou melhor explicitado, vida, terra e natureza é o que garante o sustento. O rio é o local onde se buscam os alimentos e, ao mesmo tempo, o meio para a navegação. O espaço que ocupam, onde se reproduzem, identifica o seu povo, garantindo a continuidade da etnia e a preservação de sua cultura e sua língua. A terra também é o cemitério onde os seus antepassados revivem, numa relação de espiritualidade, ao se misturar novamente com a terra. A terra está imbricada à vida deles.

Entretanto, esta incompatibilidade gera conflitos, pois são antagônicas às concepções sobre a terra por estarem em desacordo com os interesses nacionais. Assim, os direitos dos indígenas são colocados em segundo plano, em razão dos interesses capitalistas.

As terras ocupadas pelos indígenas, aos olhos da sociedade nacional, são consideradas terras que estão destinadas ao ócio e que desperdiçam a possibilidade de geração de capital, que emperram o progresso e o desenvolvimento.

Nesse sentido, o paradigma da vida reclamado por Dussel é extremamente pertinente para a análise dos direitos indígenas, pois para estes a vida sempre foi a luta primeira; a luta pelo direito originário à terra é o fundamento primeiro, pois terra é vida e vida é terra.

A tentativa do Estado de enquadrar os indígenas nas sociedades nacionais, por meio de assimilação e aculturação forçadas e, posteriormente, de enquadrar os seus direitos nas legislações nacionais, como se eles coubessem nos limites da nossa racionalidade modernizadora, foi sempre a tentativa de redução da multiplicidade à unicidade, criticada e tão bem elucidada por Dussel.

Por isso mesmo, apontamos a invisibilidade dos direitos indígenas como a negação material de suas vidas, que é o fundamento primeiro. Os direitos, embora aceitos pela lei, não encontram guarida no poder judiciário e seus titulares se convertem em seres invisíveis cada vez que tentam realizá-los (MARÉS, 1997).

As demandas econômicas, em relação às terras indígenas, produzidas pelo Estado, e com forte presença da iniciativa privada nos chamados "projetos de desenvolvimento nacional", 
têm ocasionado intensos conflitos, não só nas terras indígenas, o que já é demasiadamente grave em relação ao uso despropositado de violência contra os indígenas, mas também nas esferas dos Poderes, especialmente do judiciário que, cada vez mais, cria novas teses para a não concretização e desconstrução dos direitos territoriais originários, garantidos pela Constituição de 1988.

Assim, os grandes projetos se impõem desconsiderando a soberania dos povos indígenas, seus direitos territoriais originários, suas subjetividades, culturas, tradições, cosmovisões, ou seja, os seus direitos fundamentais, fazendo reaparecer, novamente, a tônica da violência colonial.

\section{Conclusão}

A produção intelectual do grupo modernidade/colonialidade e a filosofia da libertação permitiram repensar as categorias teóricas universalizantes impostas à América Latina pela Europa e, posteriormente, pelos países da América do Norte.

O eurocentramento da América Latina propiciou a imposição de um modelo de produção e criação de subjetividades, de imaginários e epistemes fundado no padrão de poder da colonialidade, que subjugou as populações originárias da América, tornando-os inferiores, subalternos e periféricos.

O mundo global foi normatizado e o padrão euro-norte-americano privilegiou a liberdade, a criação de direitos, a riqueza e expansão do capitalismo da metrópole em detrimento da periferia. Os sujeitos que não se encaixavam nesse padrão de poder foram considerados como o "outro" e expurgados, colocados na exterioridade do sistema mundo global.

A dominação dos indígenas, negros e mestiços, na América, iniciou com a colonização europeia e os processos descolonizatórios foram insuficientes para a libertação desses povos, que continuaram sendo vítimas da subalternização, agora por meio da colonialidade do poder.

A tônica da violência colonial se perpetuou mesmo com a chegada da modernidade, que naturalizou as relações de poder sobre estes povos com a criação científica do conceito de "raça", possibilitando, assim, que "os povos de cor" fossem inferiorizados e colonizados.

A ideação científica do conceito de raça afetou várias dimensões da vida, excluindo saberes e produções, reduzindo civilizações, valores, capacidades, criações, culturas e crenças dos vencidos da história. 
Nessa perspectiva, retoma-se o pensamento de Dussel ao reclamar um paradigma filosófico que contemple as necessidades dos espoliados da América Latina, que dê conta da violência colonial, a qual foi imposta aos indígenas, e que vige sob as estratégias de poder da colonialidade, aniquilando os direitos desses povos.

A crítica sobre a negação da vida dos excluídos-afetados, que se encontram na exterioridade do sistema mundo moderno colonial, é necessária, requerendo o urgente rompimento com essa lógica, e permeando a construção de um outro mundo possível e factível, que proporcione a realização da vida concreta dos povos indígenas.

Conclui-se, portanto, que, através da análise epistêmica, baseada na metodologia da descolonialidade, instiga-se uma mudança vital que legitima os direitos indígenas, assim como a restauração dos diferentes, dos externos e excluídos do modelo padronizado pelo poder ocidentalizado, sendo o paradigma da vida concreta o fundamento que permeia essa transformação.

\section{Referências}

BALLESTRIN, Luciana. América Latina e o giro decolonial. Revista Brasileira de Ciência Política, Brasília, n. 11, p. 89-117, maio-agosto de 2013. Disponível em: https://ayalaboratorio.files.wordpress.com/2017/06/ballestrin-luciana-amc3a9rica-latina-e-ogiro-decolonial.pdf. Acesso em: 10 mar. 2020.

BRASIL. PALÁCIO DO PLANALTO. Constituição da República Federativa do Brasil, promulgada em 05 de outubro de 1988. Brasília: Senado Federal, 2020.

BRASIL. Relatório da Comissão Nacional da Verdade. Texto 05: violações de direitos humanos dos povos indígenas. vol. II. Brasília: CNV, 2014. Disponível em: http://cnv.memoriasreveladas.gov.br/images/pdf/relatorio/Volume\%202\%20\%20Texto\%205.pdf. Acesso em: 20 fev. 2020.

BURGOS, Elizabeth. Meu nome é Rigoberta Menchú: e assim nasceu minha consciência. Tradução: Lólio Lourenço de Oliveira. Rio de Janeiro: Paz e Terra, 1993.

BUSSO, Hugo e MONTOYA, Angélica Montes. Entrevista a Ramón Grosfoguel. Polis, v. 6, n. 18, 2007. Disponível em: http://polis.revues.org/4040. Acesso em: 24 fev. 2020.

CASTRO-GÓMEZ, Santiago y GROSFOGUEL, Ramón. Prólogo. Giro decolonial, teoría crítica y pensamiento heterárquico. In: CASTRO-GÓMEZ, Santiago y GROSFOGUEL, Ramón (Orgs.). El giro decolonial: reflexiones para una diversidad epistémica más allá del capitalismo global. Bogotá: Instituto de Estudios Sociales Contemporáneos; Instituto Pensar; Pontificia Universidad Javeriana; Siglo del Hombre Editores y Universidad Central, 2007. p. 9-24. Disponível em: http://www.unsa.edu.ar/histocat/hamoderna/grosfoguelcastrogomez.pdf. Acesso em: 10 mar. 2020. 
CLASTRES, Pierre. Do etnocídio. In: CLASTRES, Pierre. Arqueologia da violência: pesquisas de antropologia política. Prefácio de Bento Prado Jr. Tradução de Paulo Neves. Publicado em 1980. São Paulo: Editora Cosac \& Naify, 2004.

DAMÁZIO, Eloise da Silveira Petter e SPAREMBERGER, Raquel Fabiana Lopes. Discurso constitucional colonial: um olhar para a decolonialidade e para o "novo" Constitucionalismo Latino-Americano. Pensar, Fortaleza, v. 21, n. 1, p. 271-297, jan./abr. 2016. Disponível em: http://periodicos.unifor.br/rpen/article/view/2939/pdf. Acesso em: 16 mar. 2020.

DUSSEL, Enrique Domingos. 1492 o encobrimento do outro: a origem do mito da modernidade. Conferências de Frankfurt / Enrique Dussel. Tradução: Jaime A. Clasen. Petrópolis: Vozes, 1993.

DUSSEL, Enrique Domingos. Europa, modernidade e eurocentrismo. In: LANDER, Edgardo (Org.). A colonialidade do saber: eurocentrismo e ciências sociais. Perspectivas latinoamericanas. Buenos Aires: Colección Sur Sur, CLACSO, 2005.

DUSSEL, Enrique Domingos. Ética da libertação: na idade da globalização e da exclusão. $2^{\text {a }}$ ed. Petrópolis: Editora Vozes, 2002.

DUSSEL, Enrique Domingos. Filosofia da Libertação na América Latina. Coleção Reflexão Latino-Americana. São Paulo: Edições Loyola; Editora Unimep, 1980.

DUSSEL, Enrique Domingos. A Filosofia da Libertação frente aos estudos pós-coloniais, subalternos e a pós-modernidade. Revista Direito e Práxis, Rio de Janeiro, v. 8, n. 4, p. 32323254, 2017. Disponível em: http://www.epublicacoes.uerj.br/index.php/revistaceaju/article/view/31230. Acesso em: 12 mar. 2020.

FOUCAULT, Michel. A Arqueologia do Saber. Rio de Janeiro: Forense Universitária, 2008.

GEDIEL, José Antônio Peres [et. al.]. Direitos em conflito: movimentos sociais, resistência e casos judicializados. vol 1. Curitiba: Kairós, 2015.

HESPANHA, António Manuel. Pluralismo Jurídico e Direito Democrático. São Paulo: Annablume, 2013.

KEHL, Maria Rita. O fio que dá sentido à vida. Publicado em 25 de novembro de 2013. Disponível em: https://www.geledes.org.br/o-fio-que-da-sentido-a-vida-maria-rita-kehl/. Acesso em: 05 abril 2020.

LAS CASAS, Bartolomé de. O paraíso destruído: a sangrenta história da conquista da América Espanhola. Tradução de Heraldo Barbuy. Porto Alegre: L\&PM, 2011.

LUDWIG, Celso Luiz. Para uma filosofia jurídica da libertação: Paradigmas da Filosofia, Filosofia da Libertação e Direito Alternativo. $2^{\mathrm{a}}$ ed. Florianópolis: Conceito Editorial, 2011.

LUDWIG, Celso Luiz. Direitos Humanos: fundamentação transmoderna. In: GEDIEL, José Antônio Peres [et. al.]. Direitos Humanos e Políticas Públicas. Curitiba: Universidade Positivo, 2014. p. 11-36. 
LUDWIG, Celso Luiz. A transformação da filosofia da libertação. Revista da Faculdade de Direito da UFPR, Curitiba, v. 44, p. 43-59, 2006. Disponível em: http://revistas.ufpr.br/direito/article/view/9414/6506. Acesso em: 19 mar. 2020.

LUDWIG, Celso Luiz. Filosofia da Libertação. In: BARRETTO, Vicente de Paulo (Org.). Dicionário de Filosofia do Direito. Unisinos: Editora Unisinos Co-edição Renovar, 2006. p. 326-333.

LUDWIG, Celso Luiz. Política da libertação: notas introdutórias a partir da filosofia de Enrique Dussel. In: SOUZA, André Peixoto de (Org.). Estado, Poder e Jurisdição. Rio de Janeiro: GZ, 2015, p. 29-58.

MACHADO, Roberto. Foucault, a ciência e o saber. Rio de Janeiro: Zahar, 2009.

MIGNOLO, Walter D. A gnose e o imaginário do sistema mundial colonial/moderno. In: Histórias locais / Projetos globais: colonialidade, saberes subalternos e pensamento liminar. Tradução de Solange Ribeiro de Oliveira. Belo Horizonte: Editora UFMG, 2003. p. 23-76.

PAZELLO, Ricardo Prestes. Direito insurgente e movimentos populares: o giro descolonial do poder e a crítica marxista ao direito. 8 agosto de 2014. 545 fls. Tese (Doutorado em Direito). Programa de Pós-Graduação em Direito da Universidade Federal do Paraná. Curitiba, 2014. Disponível em: http://acervodigital.ufpr.br/bitstream/handle/1884/36287/R\%20-\%20T\%20\%20RICARDO\%20PRESTES\%20PAZELLO.pdf?sequence=1. Acesso em: 05 mar. 2020.

PORTO-GONÇALVES, Carlos Walter. De saberes e de territórios: diversidade e emancipação a partir da experiência latino-americana. In: De los saberes de la emancipación y de la dominación. Buenos Aires: CLACSO, 2008. Disponível em: http://biblioteca.clacso.edu.ar/clacso/gt/20160224041201/04porto.pdf. Acesso em: 02 mar. 2020.

PORTO-GONÇALVES, Carlos Walter. Da geografia às geo-grafias: um mundo em busca de novas territorialidades. In: La Guerra Infinita: Hegemonía y terror mundial. Buenos Aires: CLACSO, 2002.2 Disponível em: http://bibliotecavirtual.clacso.org.ar/clacso/gt/20101018013328/11porto.pdf. Acesso em: 02 mar. 2020.

QUIJANO, Aníbal. Bien Vivir: entre el desarrollo y la des/colonialidad del poder. In: QUIJANO, Aníbal. (Org.). Des/colonialidade y bien vivir: un nuevo debate en América Latina. 1 ed. Lima: Editorial Universitaria; Cátedra América Latina y la Colonialidad del Poder; Universidade Ricardo Palma, 2014.

QUIJANO, Aníbal. Colonialidade do poder e classificação social. In: SANTOS, Boaventura de Sousa; MENESES, Maria Paula (Orgs.). Epistemologias do Sul. Coimbra: Almedina, 2009. p. 73-115.

QUIJANO, Aníbal. Colonialidad del poder y clasificación social. In: CASTRO-GÓMEZ, Santiago y GROSFOGUEL, Ramón (Orgs.). El giro decolonial: reflexiones para una diversidad epistémica más allá del capitalismo global. Bogotá: Instituto de Estudios Sociales Contemporáneos; Instituto Pensar; Pontificia Universidad Javeriana; Siglo del Hombre Editores y Universidad Central, 2007. p. 93-125. Disponível em: 
http://www.unsa.edu.ar/histocat/hamoderna/grosfoguelcastrogomez.pdf. Acesso em: 05 mar. 2020.

QUIJANO, Aníbal. Colonialidade do poder, eurocentrismo e América Latina. In: LANDER, Edgardo (org.). A colonialidade do saber: eurocentrismo e ciências sociais - perspectivas latino-americanas. Tradução de Júlio César Casarin Barroso Silva. Buenos Aires: CLACSO, 2005, p. 227-278.

QUIJANO, Aníbal. Dom Quixote e os moinhos de vento na América Latina. Dossiê América Latina. Estudos Avançados, 19 (55), 2005. Disponível em: http://www.scielo.br/pdf/ea/v19n55/01.pdf. Acesso em: 05 mar. 2020.

QUIJANO, Aníbal. El movimiento indígena y las cuestiones pendientes en América Latina. El Cotidiano, México, v. 23, n. 151, p. 107-120, septiembre-octubre/2008. Disponível em: http://www.redalyc.org/pdf/325/32511865013.pdf. Acesso em: 05 mar. 2020.

QUIJANO, Aníbal. Notas sobre a questão da identidade e nação no Peru. Estudos Avançados, 6(16), 1992.

QUIJANO, Aníbal. ¡Qué tal Raza!. In: Ecuador Debate. Etnicidades e identificaciones. n. 48, diciembre 1999, p. 141-152, Quito: CAAP. Disponível em: http://repositorio.flacsoandes.edu.ec/handle/10469/5724\#.Wme9aq6nHIU. Acesso em: 05 mar. 2020.

QUIJANO, Aníbal. Un fantasma recorre el mundo. Estudos Avançados, 12(34), 1998.

QUIJANO, Aníbal. Otro horizonte de sentido histórico. América Latina em movimento, n. 441, p. 2-5, febrero de 2009. Disponível em: https://www.alainet.org/sites/default/files/alai441w.pdf. Acesso em: 05 mar. 2020.

QUIJANO, Aníbal. (Org.). Cuestiones y horizontes: de la dependencia histórico-estructural a la colonialidad/descolonialidad del poder. Selección y prólogo a cargo de Danilo Assis Clímaco. Coleccíon Antologías. 1 ed. Ciudad Autónoma de Buenos Aires: CLACSO, 2014.

RIBEIRO, Darcy. O Povo Brasileiro: a formação e o sentido do Brasil. São Paulo: Companhia das Letras, 1995.

SEGATO, Rita Laura. Aníbal Quijano y la perspectiva de la colonialidad del poder. In: QUIJANO, Aníbal. (Org.). Des/colonialidade y bien vivir: un nuevo debate en América Latina. 1 ed. Lima: Editorial Universitaria; Cátedra América Latina y la Colonialidad del Poder; Universidade Ricardo Palma, 2014. p. 35-72.

SOUZA FILHO, Carlos Frederico Marés de. O renascer dos povos indígenas para o Direito. Curitiba; Juruá, 1998.

SOUZA FILHO, Carlos Frederico Marés de. Os direitos invisíveis. Texto apresentado no XXI Encontro Anual da ANPOCS, 1997.

SOUZA FILHO, Carlos Frederico Marés de. O direito envergonhado (O direito e os índios no Brasil). Revista IIDH, Costa Rica, v. 15, p. 145-165, jan./jun. 1992. 
SOUZA FILHO, Carlos Frederico Marés de. Os direitos invisíveis. Texto apresentado no XXI Encontro Anual da ANPOCS, 1997.

WOLKMER, Antonio Carlos. Paradigmas, historiografia crítica e direito moderno. Revista da Faculdade de Direito UFPR, Curitiba, a. 28, n. 28, p. 55-67, 1994/95. Disponível em: http://revistas.ufpr.br/direito/article/view/9368/6461. Acesso em: 29 mar. 2020.

WOLKMER, Antonio Carlos. [et. al.]. Historicidade Crítica do Constitucionalismo LatinoAmericano e Caribenho. Revista Direito e Práxis, Rio de Janeiro, v. 8, n. 4, p. 2843-2881, 2017. Disponível em: http://www.e-

publicacoes.uerj.br/ojs/index.php/revistaceaju/article/view/31217/22177. Acesso em: 18 mar. 2020 . 